\title{
VOLUNTEER WORK, INFORMAL HELP, AND CARE AMONG THE 50+ IN EUROPE: FurTher EVIDENCE FOR 'LINKED' PRODUCTIVE ACtivities AT Older AGES
}

Karsten Hank \& Stephanie Stuck 


\title{
Volunteer Work, Informal Help, and Care among the 50+ in Europe: Further Evidence for 'Linked' Productive Activities at Older Ages
}

\author{
Karsten Hank ${ }^{\mathrm{a}} \&$ Stephanie Stuck
}

\begin{abstract}
Taking a cross-national perspective, we investigate linkages between volunteer work, informal help, and care among Europeans aged 50 or older. Based on 27,305 personal interviews from the 2004 Survey of Health, Ageing and Retirement in Europe, we estimate univariate and multivariate probit models, which allow us to analyze the interrelationship between different productive activities. There is substantial variation in the participation in volunteering, helping, and caring between countries and regions. Independent of the general level of activity in a country, we find evidence for a complementary and interdependent relationship between all three activities. Our findings not only suggest an important role of societal opportunity structures in elders' productive engagement, but also support notions of the existence of a general motivation for engagement in productive activities.
\end{abstract}

\section{Acknowledgements}

We would like to thank Marcel Erlinghagen and Jürgen Maurer for comments and advice. Financial support for this research was provided by the Fritz Thyssen Foundation through the project 'Informal Work of Elders in Germany and Europe'. This paper is based on data from Release 2.0.0 of SHARE 2004. The SHARE data collection has been primarily funded by the European Commission through the $5^{\text {th }}$ framework program (project QLK6-CT-2001-00360 in the thematic program 'Quality of Life'). Additional funding came from the U.S. National Institute on Aging (U01 AG09740-13S2, P01 AG005842, P01 AG08291, P30 AG12815, Y1AG-4553-01, and OGHA 04-064). Data collection in Austria (through the Austrian Science Fund, FWF), Belgium (through the Belgian Science Policy Office), and Switzerland (through BBW/OFES/UFES) was nationally funded. Further support by the European Commission through the $6^{\text {th }}$ framework program (Project RII-CT-2006-062193, SHARE-I3) is gratefully acknowledged.

\footnotetext{
a MEA - University of Mannheim \& DIW Berlin. Address for correspondence: MEA, Building L13-17, D-68131 Mannheim, Germany. Phone: +49-621-181-3439. Fax: +49-621-181-1863. Email: hank@mea.uni-mannheim.de.

${ }^{\mathrm{b}}$ MEA - University of Mannheim.
} 


\section{Introduction}

Since Butler \& Gleason (1985) introduced the term 'productive aging', a large number of empirical studies have been conducted showing that a substantial proportion of the older population engages in a variety of productive activities beyond gainful employment (for overviews see Avramov \& Maskova 2003; Morrow-Howell et al. 2001). A set of recent crossnational analyses suggests that the individual-level determinants of activity, both in the older and in the general population, are fairly stable across different institutional contexts, but that the baseline probability of engaging in productive activites varies substantially. Particularly wellinvestigated examples are formal volunteering (e.g., Erlinghagen \& Hank 2006; Salamon \& Sokolowski 2003; Schofer \& Fourcade-Gourinchas 2001) and informal caring (e.g., Alber \& Köhler 2004; Attias-Donfut et al. 2005; Motel-Klingebiel et al. 2005). Similar cross-country patterns are found irrespective of the specific activity under investigation, which may lead us to conclude that there are countries with opportunity structures that facilitate or necessitate individuals' productive engagement in general.

While taking a cross-national comparative perspective - exploiting data from the 2004 Survey of Health, Ageing and Retirement in Europe - it is the primary aim of our analysis to investigate linkages between volunteer work, informal helping, and caring at the level of the individual actor: Is the relationship between these activities characterized by complementarity or by substitution? Is there evidence for the existence of (unobserved) personality traits that foster engagement independent of a specific domain? To begin with, we provide a brief overview of recent studies addressing the connection between different dimensions of productive aging. After a short description of our data source and methods, we present descriptive findings on the participation of older Europeans in volunteering, helping, and caring. Eventually, we estimate univariate and multivariate probit models, which allow us to analyze the interrelationship between different productive activities and the determinants of older individuals' engagement therein. The final section concludes. 


\section{Complementarity or substitution between productive activities?}

With regard to the interrelation between various productive activities, two major approaches with different basic assumptions can be distinguished. On the one hand, taking up a new activity might either compensate the loss of previous active roles (role substitution; e.g., Chambré 1984), or it might result in giving up or reducing the intensity of other activities due to time constraints. On the other hand, multiple activities performed in parallel may complement each other, thus leading to an overall greater productive engagement (role extension; cf. Choi et al. 2007; Mutchler et al. 2003).

Empirical research investigating the relationship between, for example, labor force participation and informal caring (e.g., Dentinger \& Clarkberg 2002; Pavalko \& Artis 1997) or volunteering (e.g., Mutchler et al. 2003; Wilson \& Musick 2003), produced mixed results, but tend to show a negative association between employment and caring, and a positive one with volunteering. Studies focusing on the role of caring in formal and informal voluntary engagement suggest that caregiving does generally not have a negative impact on the propensity or the intensity of volunteering (e.g., Burr et al. 2005; Choi et al. 2007; Farkas \& Himes 1997). Analyzing longitudinal data from the Health and Retirement Study, Choi et al. (2007) found evidence that wives who cared for their husbands were less likely to engage in formal volunteering or informal helping at all. If, however, the individual's commitment to formal volunteering exceeded four hours per week, her caregiving status was not a deterrent to voluntary engagement. This is largely consistent with Burr et al. (2005), who found that older adult caregivers were generally more likely to be volunteers than noncaregivers, and that those who provided higher numbers of caregiving hours also reported a greater number of volunteer hours than did noncaregivers. Two main mechanisms have been proposed to explain this relationship. First, performing voluntary work outside of a caregiving relationship allows compensating the emotional burden and stress experienced there (e.g., Choi et al. 2007; Rozario et al. 2004). Second, compared to noncarers, caregivers tend to get involved with larger social 
networks, including charitable organizations, which may provide opportunities for engaging in voluntary activities (e.g., Burr et al. 2005; Farkas \& Himes 1997).

Wilson \& Musick (1997) pointed out that formal volunteering and informal volunteering (or helping) constitute distinct forms of productive engagement, showing that formal volunteering has a positive effect on helping, but that helping does not affect formal volunteering. While other authors (cf. Erlinghagen 2000) suggested that the main distinguishing feature between these two types of voluntary work should be seen in their respective degree of formalization and their different organizational contexts, Wilson \& Musick (1997: 700; italics in the original) propose that differences in the perceived degree of obligation matter the most: "obligations have a more powerful influence on informal helping than they do on formal volunteer work." Along the same lines, Burr et al. (2005: S247) define formal volunteering as "a discretionary activity for most persons", while informal caring "is often considered an obligatory activity, especially when the care recipient is a family member."

The degree of obligation by which specific activities are characterized matters greatly for the probability to be engaged in a certain domain (cf. Gallagher 1994), and the experience of reward for one's efforts is critical for the effects of productive engagement on well-being (e.g., Siegrist 2004). So far, barely any empirical evidence has been presented supporting concerns that engagement in multiple productive roles might negatively affect older people's health (role strain) - on the contrary, there is rather indication for a positive relationship (role enhancement; e.g., Baker et al. 2005; Glaser et al. 2006; Rozario et al. 2004). Burr et al. (2005: S255) argue "that in the population of older persons there may be a class of individuals who could be characterized as 'super helpers' or 'doers'. That is, some persons have high commitments to helping others in both the private and public domains, and they possess the necessary resources to act on these commitments." A related pilot study conducted by Caro et al. (2005) investigated, whether multiple (productive) role occupancy at older ages could be explained by personality traits that work independent of a specific activity, such as an internalized general attitude of altruism or a general motivation to be active. Although the authors find some 
indication that general motivations, in addition to specific motives, play a role in the activity patterns observed in their study, it is yet unclear, which personality traits in particular matter here - and how they might be identified empirically.

\section{Method}

The ,Survey of Health, Ageing and Retirement in Europe'

Our data are drawn from Release 2.0.0 of the 2004 baseline wave of the Survey of Health, Ageing, and Retirement in Europe (SHARE; cf. Börsch-Supan et al. 2005). The survey is closely modelled after the U.S. Health and Retirement Study and is the first dataset to provide extensive standardised information on the socio-economic status, health, and family relationships of older people in multiple European countries. Our analytic sample contains data from 27,305 personal interviews with people aged 50 or more years in 11 countries: Sweden, Denmark, Germany, The Netherlands, Belgium, France, Switzerland, Austria, Italy, Spain, and Greece. Probability samples were drawn in each participating country, although the institutional conditions in the participating countries are so different that a uniform sampling design was impossible. They varied from a simple random selection of households, from the central population register, as in Denmark, to complex multi-stage designs, as in Greece (where the telephone directory was used as a sampling frame). The weighted average household response rate was $60 \%$, and ranged from $39 \%$ in Switzerland to $79 \%$ in France (a thorough account is presented in Börsch-Supan \& Jürges 2005). - Descriptive sample statistics are presented in Table 1.

[Table 1 about here]

Measurement of volunteer work, informal help, and care

The information on the respondents' engagement in volunteering, informal helping, and caregiving on which our analysis is based refers to a question in SHARE on social participation 
in general, which allowed for multiple answers: "Please look at card 35. Have you done any of these activities in the last month?" The answer categories that we take into consideration are:

\section{Done voluntary or charity work \\ 2. Cared for a sick or disabled adult \\ 3. Provided help to family, friends or neighbors}

While many studies focus on membership in voluntary associations (e.g., Schofer \& FourcadeGourinchas 2001), we exploit information on whether the respondent has been actively engaged in voluntary or charity work during the month before the interview. Although membership is highly correlated with activity, the former measure might lead to an overestimation of actual engagement. Since volunteer work is often performed occasionally rather than regularly and other studies' retrospective questions regarding participation cover a longer period of time (e.g. the last year), our figures are even more likely to give a very conservative estimate of the prevalence of volunteering in the SHARE countries (cf. Erlinghagen \& Hank 2006).

When interpreting the respondent's information on care and help, it is important to consider that in a questionnaire module prior to the general activity question which we use, detailed questions were asked, addressing care and help provided within and outside of the respondent's household over the past 12 months (cf. Attias-Donfut et al. 2005). Respondents who already reported such activities in this 'social support' module might not have mentioned help or care provided over the past month to avoid repetition. Moreover, care within one's own household is likely to be underestimated, because the context in which the underlying question is framed suggests an interpretation of its meaning that rather refers to engagement external to the household.

\section{Control variables}

The selection of control variables for our analysis is based on the assumption that individuals need to be equipped with resources in order to engage in productive activities (e.g., Tang 2006; Wilson \& Musick 1997). Relevant demographic characteristics are sex, age (50-64, 65-74, 75 
years or older), and partnership status (living with or without a partner). The individual's socioeconomic status is measured by the employment status (employed, not employed, retired) and the highest educational degree ever achieved (low, medium, or high, based on the ISCED 97 classification). Furthermore, we include three binary health indicators: self-perceived general health ('good or better' versus 'fair or worse'), chronic conditions ('2 or more' versus ' 1 or none'), and symptoms of depression (based on the EURO-D scale) in the month preceding the interview. These individual-level variables are complemented by regional indicators, which allow us to distinguish between groups of countries, for which we identified similar activity patterns (see our descriptive findings below).

\section{The multivariate probit model}

In a first step of analysis we estimate univariate probit models for the binary dependent variables 'volunteer work', 'informal help', and 'care'. Subsequently, we estimate a multivariate probit model to estimate outcomes for these three variables simultaneously (cf. Cappellari \& Jenkins 2003; Greene 2000: Chapter 19.6). The multivariate probit model allows the coefficients of the regressors to vary with each dependent variable and enables us to explore whether there are correlations between unobservable characteristics $(\rho)$ associated with each outcome. A statistically significant correlation of the error terms across equations would suggest an interdependent relationship between the decisions to volunteer, to help, and/or to care. Such a relationship could be interpreted as indication for the existence of both relevant societal opportunity structures and/or personality traits related to a general motiviation to be active, as proposed by Burr et al. (2005) and Caro et al. (2005), for example. 


\section{Results}

Descriptive findings

Across all SHARE countries, an average of 10 percent of the population aged 50 or older engaged in voluntary work in the month preceding the interview (Figure 1a). Between countries, however, substantial variation in the proportion of active elders is found. Belgium, Denmark, Sweden, and particularly the Netherlands ( 21 percent) are characterized by the highest shares of elders reporting to have volunteered. Austria, France, Germany, and Switzerland constitute a group of countries with medium participation, whereas the the proportions of volunteers in Italy, Greece, and especially Spain ( 2 percent) are clearly below the average (see Erlinghagen \& Hank, 2006, for a detailed description).

Almost one fifth of the respondents provided informal help for family, friends, or neighbors (Figure 1b). Cross-country differences here follow a pattern which is very similar to the one observed for volunteering. Belgian, Danish, Dutch and the top-ranking Swedish (37 percent) elders are followed by their counterparts in Austria, France, and Switzerland, where about 20 percent of the population 50+ provided help. While below average proportions of helpers are also found in Germany, Greece, and Italy, the prevalence of informal help is by far lowest in Spain (6 percent).

The average share of active caregivers is 5 percent (Figure 1c). Although we also detect cross-national differences here, the spatial pattern (in terms of a North-South gradient) is less clear. Belgium has the highest share of carers in the older population ( 9 percent), closely followed by Austria, the Netherlands, Sweden, and Switzerland. While the respective proportions in Denmark, France, and Germany reflect the continental European average, only 23 percent of Italian and Spanish elders report to have cared for a sick or disabled adult in the previous month.

[Figure 1 about here] 
A joint consideration of formal volunteering, informal helping, and caring (details not shown) reveals that 26 percent of the population aged 50 and over engaged in at least one of the three productive activities covered in our study. The proportion of volunteers among those who provided informal help (19 percent) or care (27 percent) is clearly higher than in the general population (10 percent). The same holds for helpers and caregivers. While 18 percent of all elders helped, the respective share among volunteers is 34 percent and as high as 45 percent among caregivers. The proportion of carers, constituting 5 percent of the general population aged 50+, is almost three times higher in the group of older adults who volunteer (14 percent) or provide informal help (13 percent). Similarly strong bivariate associations between various productive activities are found in all SHARE countries (cf. Erlinghagen \& Hank 2006: Table 2).

In sum, we generally detect the highest shares of active elders in the Scandinavian countries, Belgium, and the Netherlands, whereas Austria, France, Germany, and Switzerland constitute a 'medium' group of countries, followed by Greece, Italy, and Spain, which are characterized by the lowest activity rates. Although the rank order of countries varies slightly depending on the specific activity under consideration, there is a remarkably stable regional grouping: those countries with high proportions of active elders in one domain also exhibit an above average engagement of their older population in other kinds of productive activities. The only exception from this pattern is the high share of carers in Greece and the relatively low proportion of Danish caregivers.

\section{Multivariate results}

The results of the univariate probit models for the dependent variables 'volunteer work', 'informal help', and 'care' universally document the great importance of individual resources for engaging in productive activities (Table 2). With regard to the probability to be active, we generally find a negative age gradient. While the respondent's sex does not contribute to an explanation of differences in voluntary engagement, women are more likely to provide informal help or care. Partnership status bears no statistically significant association with any of the 
dependent variables. We detect a positive educational gradient independent of a specific activity, but the relationship between having obtained a higher educational degree and the probability to be active is more pronounced, if formal volunteering rather than helping or caring is considered. The negative association between the non-market productive activities in our study and gainful employment (vs. retirement) is also strongest in the model for volunteer work (the respective coefficient in the 'care' regression is even insignificant). It is interesting to note that the probability to provide informal help for those who are not employed is lower than for retirees, which might point to an enduring role of social networks established during one's work life.

A fairly irregular picture emerges with regard to the relationship between the dependent variables and the various health indicators we account for in the analysis. The propensity to volunteer is significantly lower among those who perceive their own general health as fair or worse or who report symptoms of depression. A negative correlation is also detected between poor self-perceived health and informal helping. Respondents suffering from two or more chronic diseases, however, are more likely to help. Particularly noteworthy in the model for caring is the highly significant coefficient of the depression indicator. Its positive sign suggests that elders suffering from mental problems are more likely to care than their healthier counterparts (cf. Sherwood et al. 2005).

In all models, we find a strongly positive and highly significant correlation between the dependent variable and other productive activities. That is, even if other individual characteristics are controlled for, there is evidence for an increase in the probability to be active in one domain with parallel productive engagement in other domains. This relationship holds in similar ways across all three groups of countries identified in the descriptive analysis (details of interaction models not shown here). Moreover, the observed differences between these regional clusters with regard to the individual's propensity to perform productive activities remain siginificant even if all control variables are included in the regression. While Scandinavian, Belgian, and Dutch elders exhibit the highest probability to engage in formal volunteering and 
informal helping, the propensity of older adults from the Mediterranean countries to be active here is lowest (see also Hank \& Erlinghagen 2006). The univarite probit models provide no statitically significant evidence for cross-country differences in the probability to care, though.

[Table 2 about here]

The univariate probit models suggest that the positive association between the various dimensions of productive aging in our analysis might be driven by a joint, unobserved determinant. This possibility is accounted for in the simultaneous estimation of the probabilities to engage in volunteering, helping, and caring. The multivariate probit model constitutes a reduced form model, because only the exogenous control variables are entered on the right-hand side of the regression, whereas the (endogenous) activity variables are excluded. This model basically confirms the results of the previous models. However, some formerly marginally significant or even insignificant coefficients now meet the standards of more rigid levels of statistical significance (Table 3). This is particularly the case in the 'care' model, where we now find the same pattern of cross-country differences already known from the estimation of the probabilities to volunteer and to help: respondents from the Mediterranean countries exhibit the lowest propensity to act as caregivers for sick or disabled adults, whereas the probability to do so is highest in the northern European countries (including Belgium and the Netherlands).

The most important finding from the multivariate probit model is, however, that the correlation between the error terms of all three equations is highly significant. The correlation between 'volunteer work' and 'informal help' turns out to be weakest $(\rho=.19)$, while the correlation between 'informal help' and 'care' is strongest $(\rho=.31)$. A likelihood ratio test rejects the hypothesis of independence between the three equations. Estimating the same model separately for each country group (details not shown) provides no indication for regional differences in the structure of the associations described here. 
[Table 3 about here]

\section{Discussion}

This article portrays a picture showing that many older Europeans are engaged in a variety of productive activities beyond gainful employment. On average, over the last month preceding the SHARE interview, $10 \%$ of Europe's generation $50+$ performed volunteer work, $18 \%$ engaged in informal helping, and 5\% cared for a sick or diabled adult. However, participation in all three activities varies substantially between countries and regions. Generally speaking, the largest proportions of active elders are found in the Scandinavian countries as well as in Belgium and the Netherlands, followed by Austria, France, Germany, and Switzerland with 'medium' levels of participation, whereas Greece, Italy, and Spain are characterized by the lowest rates of productive engagement in the older population. These findings are consistent with studies proposing that societal patterns of activity are connected with elements of family or welfare state regimes (e.g., Pichler \& Wallace 2007; Salamon \& Sokolowski 2003), which reflect, for example, variations in institutional opportunities to engage in productive activities (cf. Smith \& Shen 2002).

Independent of the general level of participation in a country, we also find evidence for a complementary relationship between volunteer work, informal help, and care at the individuallevel. While, in our sample, employment tends to be negatively associated with the propability to engage in unpaid productive activities, we detect a strong positive correlation between active involvement in one domain and the propensity to be engaged elsewhere. This confirms results reported in a number of recent U.S. studies (e.g., Burr et al. 2005; Choi et al. 2007). Moreover, the interdependence between the simultaneously estimated outcomes of volunteering, helping, and caring - which we detected in the multivariate probit model - provides further evidence for the existence of a general motivation to be active (cf. Caro et al. 2005), which appears to be independent of a specific domain of activity and significant for the individual's decision about 
his or her productive engagement, even when relevant individual resources, such as education or health, are controlled for.

The correlation of the error terms in the multivariate probit model might also reflect the existence of opportunity structures (e.g. a local senior center), which are initially associated with one specific activity (e.g. community volunteering in that center), but may also have an impact on the probability to get actively involved in other domains (e.g. caring for a frail friend whom you met there). We interpret the differential strength of the $\rho$ 's in the sense that such opprtunities appear to be less important in the relationship between formal volunteering and informal helping, whereas they seem more relevant if the connection between caring and helping is considered (cf. Farkas \& Himes 1997; Wilson \& Musick 1997). This might indicate that informal 'helping' and 'caring', which we treat as separate spheres of activity, may in fact be closely related domains. While helping and caring describe different activity contents, both are performed within informal social networks. That is, the organizational context in which these activities are done is very similar and clearly distinct from the one in which, for example, voluntary work is usually performed (charities, social clubs, political parties). These results call for a clearer conceptual and empirical distinction between the content and the organization of productive activities (cf. Erlinghagen 2000).

Against the background of our research, a number of immediate further issues emerge, which should be addressed in future work (also see Wilson 2005). While we have taken the perspective of the individual, recent studies by Rotolo \& Wilson (2006) and Hook (2004) analyzed formal volunteering and informal support in the family context. The latter showed that voluntary work "is not allocated in isolation from paid work and domestic work, but is part of the gendered household labor allocation process determined, in part, by time constraints." (Hook 2004: 115) This enhanced approach - regarding both the unit of analysis and the activities considered in the analysis - could also prove to be fruitful for future studies of productive aging. Moreover, longitudinal SHARE data (cf. Börsch-Suapn et al. 2005: Chapter 
1), which are currently being collected, will allow analyses of the relationship between different productive activities over time.

Probably the most important, but also most difficult issue for future research is the study of motivations, which needs to be grounded better in action theory and also needs further development with regard to its empirical operationalization. The psychological literature already offers numerous studies on the motivations for engaging in a variety of socially productive activities (e.g., Clary \& Snyder 1999; Penner et al. 2005) and Siegrist et al. (2004: 7) point to "a basic principle in social production theory that states that people, in general, aim at maintaining and improving their well-being through performing productive activities." These approaches need to be complemented, however, by a thorough model of action, which explicitly accounts for the individual benefits of 'non-profit' productive acticities, such as the enhancement of sefefficay and self-esteem (Siegrist et al. 2004: 7f.), the production of social capital (Pichler \& Wallace 2007), or the reduction of transaction costs (Erlinghagen 2003). It remains unclear yet, how these various components of utility specifically interact to lead to the patterns of productive ageing we observe and which are often characterized by multiple active roles - or the absence of any productive engagement.

\section{References}

Alber, J / Köhler, U. (2004): Health and Care in an Enlarged Europe. European Foundation for the Improvement of Living and Working Conditions, Office for Official Publications of the European Communities, Luxembourg.

Attias-Donfut, C. / Ogg, J. / Wolff, F.-C. (2005): European patterns of intergenerational financial and time transfers. European Journal of Ageing 2, 161-173.

Avramov, D. / Maskova, M. (2003): Active Ageing in Europe - Volume 1 (Population Studies Series No. 41). Council of Europe Publishing: Strasbourg. 
Baker, L.A. / Cahalin, L.P. / Gerst, K. / Burr, J.A. (2005): Productive activities and subjective well-being among older adults: The influence of number of activities and time commitment. Social Indicators Research 73, 431-458.

Börsch-Supan, A. et al. (Hrsg.) (2005): Health, Ageing and Retirement in Europe - First Results from the Survey of Health, Ageing and Retirement in Europe. MEA: Mannheim.

Börsch-Supan, A. / Jürges, H. (2005): The Survey of Health, Ageing and Retirement in Europe Methodology. MEA: Mannheim.

Burr, J.A. / Choi, N.G. / Mutchler, J.E. / Caro, F.C. (2005): Caregiving and volunteering: Are private and public helping behaviours linked? Journal of Gerontology - Social Sciences 60B, S247-56.

Butler, R.N. / Gleason, H.P. (eds.) (1985): Productive Aging: Enhancing Vitality in Later Life. Springer: New York.

Cappellari, L. / Jenkins, S.P. (2003): Multivariate probit regression using simulated maximum likelihood. The Stata Journal 3, 278-294.

Caro, F.G. / Bruner-Canhoto, L. / Burr, J. / Mutchler, J. (2005): Motivation for Active Aging: Results of a Pilot Study. Working Paper, Gerontology Institute - University of Massachusetts Boston.

Choi, N.G. / Burr, J.A. / Mutchler, J.E. / Caro, F.G. (2007): Formal and Informal Volunteer Activity and Spousal Caregiving Among Older Adults. Research on Aging 29, 99-124.

Clary, E.G. / Snyder, M. (1999): The motivations to volunteer: Theoretical and practical considerations. Current Directions in Psychological Science 8, 156-159.

Dentinger, E. / Clarkberg, M. (2002): Informal Caregiving and Retirement Timing among Men and Women. Journal of Family Issues 23, 857-879.

Erlinghagen, M. (2000): Informelle Arbeit. Ein Überblick über einen schillernden Begriff [Informal Work - A General View on a Dazzling Concept]. Schmollers Jahrbuch Journal of Applied Social Science Studies 120, 239-274. 
Erlinghagen, M. (2003): Die individuellen Erträge ehrenamtlicher Arbeit. Zur sozioökonomischen Theorie unentgeltlicher, haushaltsextern organisierter Produktion [The Individual Returns to Volunteer Work. A Contribution to a Theory of Unpaid and Non-Domestic Private Production]. Kölner Zeitschrift für Soziologie und Sozialpsychologie 55, 737-757.

Erlinghagen, M. / Hank, K. (2006): The Participation of Older Europeans in Volunteer Work. Ageing \& Society 26, 567-584.

Farkas, J.I. / Himes, C.L. (1997): The Influence of Caregiving and Employment on the Voluntary Activities of Midlife and Older Women. Journal of Gerontology - Social Sciences 52B, S180-S189.

Gallagher, S.K. (1994): Doing their share: Comparing patterns of help given by older and younger adults. Journal of Marriage and the Family 56, 567-578.

Glaser, K. / Evandrou, M. / Tomassini, C. (2006): Multiple role occupancy and social participation among midlife wives and husbands in the United Kingdom. International Journal of Aging \& Human Development 63, 27-47.

Greene, W.H. (2000): Econometric Analysis (4. Auflage), Prentice Hall.

Hook, J.L. (2004): Reconsidering the division of household labor: Incorporating volunteer work and informal support. Journal of Marriage and Family 66, 101-117.

Morrow-Howell, N. / Hinterlong, J./ Sherraden, M. (Hrsg.) (2001): Productive Aging: A Conceptual Framework. Johns Hopkins University Press: Baltimore.

Motel-Klingebiel, A. / Tesch-Römer, C. / von Kondratowitz, J. (2005): Welfare states do not crowd out the family: evidence for mixed responsibility from comparative analyses. Ageing \& Society 25, $863-882$.

Mutchler, J.E. / Burr, J.A. / Caro, F.G. (2003): From Paid Worker to Volunteer: Leaving the Paid Labor Force and Volunteering in Later Life. Social Forces 81, 1267-1293.

Pavalko, E.K. / Artis, J.E. (1997): Women's caregiving and paid work: Casual relationships in late midlife. Journal of Gerontology - Social Sciences 52B, S170-S179. 
Penner, L.A. / Dovidio, J.F. / Pillavin, J.A. / Schroeder, D.A. (2005): Prosocial behavior: Multilevel perspectives. Annual Review of Psychology 56, 365-392.

Pichler, F. / Wallace, C. (2007): Patterns of Formal and Informal Social Capital in Europe. European Sociological Review 23, forthcoming.

Rotolo, T. / Wilson, J. (2006): Substitute or complement? Spousal influence on volunteering. Journal of Marriage and Family 68, 305-319.

Rozario, P.A. / Morrow-Howell, N. / Hinterlong, J.E. (2004): Role enhancement and role strain. Assessing the impact of multiple productive roles on older caregiver well-being. Research on Aging 26, 413-428.

Salamon, L.M. / Sokolowski, S.W. (2003): Institutional Roots of Volunteering: Toward a Macro-Strucutral Theory of Individual Voluntary Action, in: P. Dekker \& L. Halman (eds.), The Values of Volunteering. Cross-Cultural Perspectives. Kluwer Academic / Plenum Publishers: New York u.a., 71-90.

Schofer, E. / Fourcade-Gourinchas, M. (2001): The structural contexts of civic engagement: Voluntary association membership in comparative perspective. American Sociological Review 66, 806-828.

Sherwood, P.R. / Given, C.W. / Given, B.A. / von Eye, A. (2005): Caregiver burden and depressive symptoms. Journal of Aging and Health 17, 125-147.

Siegrist, J. / von dem Knesebeck, O. / Pollack, C.E. (2004): Social productivity and well-being of older people: A sociological exploration. Social Theory \& Health 2, 1-17.

Smith, D.H. / Shen, C. (2002): The roots of civil society: A model of voluntary assiciation prevalence applied to data on larger contemporary nations. International Journal of Comparative Sociology 43, 93-133.

Tang, F. (2006). What resources are needed for volunteerism? A life course perspective. Journal of Applied Gerontology 25, 375-390. 
Wilson, J. (2005): Some Things Social Surveys Don't Tell Us About Volunteering, in: A.M. Omoto (ed.), Community Change and Social Action. Lawrence Erlbaum Associates: Mahwah, NJ, 11-27.

Wilson, J. / Musick, M. (1997): Who cares? Towards an integrated theory of volunteer work. American Sociological Review 62, 694-713.

Wilson, J. / Musick, M (2003): Doing well by doing good: Volunteering and occupational achievement among American women. Sociological Quarterly 44, 433-450.

\section{Figure \& Tables}


Figure 1: Proportions of volunteers, informal helpers, and carers in the population 50+

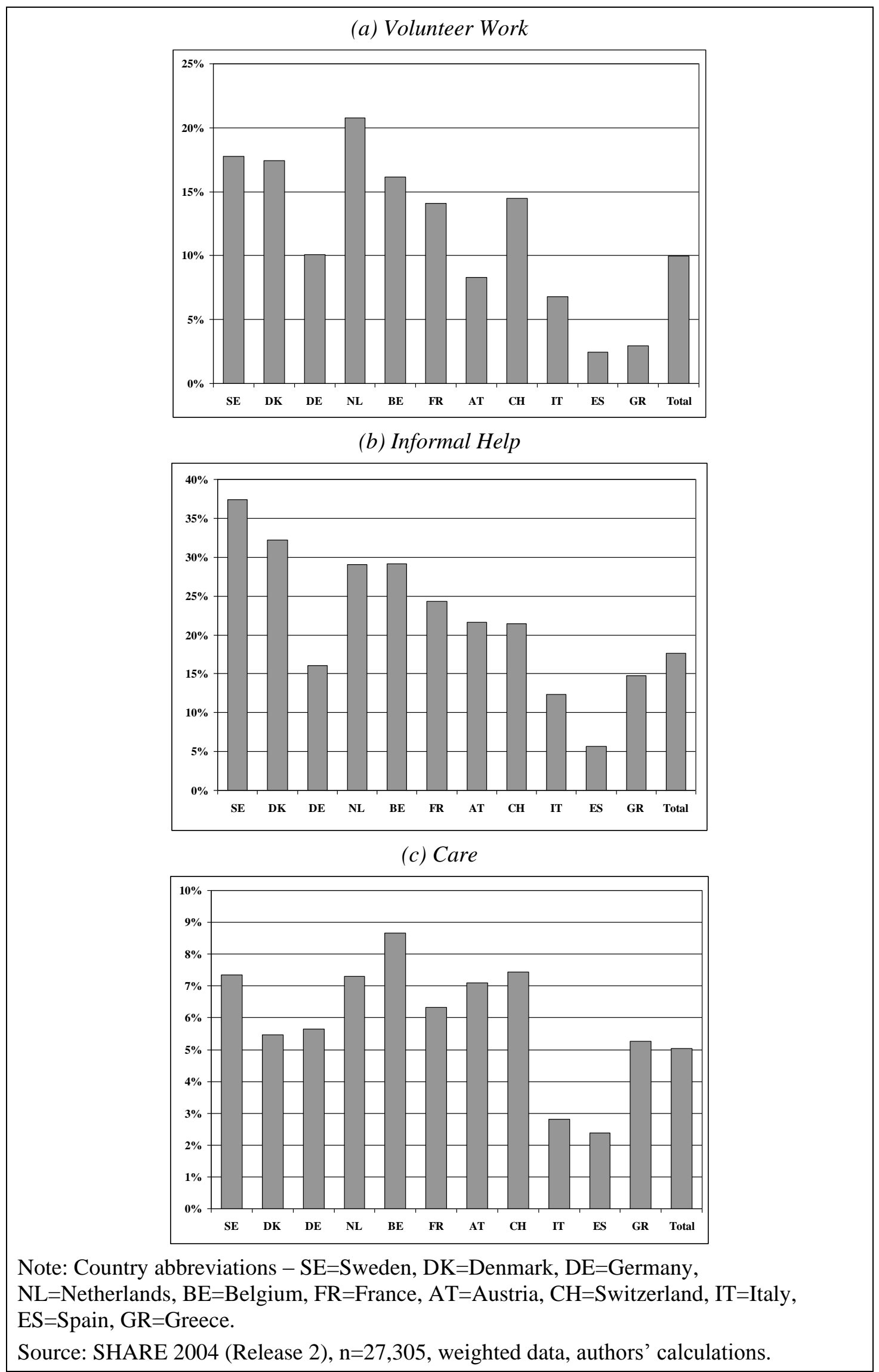


Tabel 1: Descriptive sample statistics

Proportion in \% (unweighted)

Productive activities

Volunteer work

12

Informal help

Care

Demographic characteristics

Sex (female)

Age 50-64

Age 65-74

Age $75+$

Living with a partner

Socio-economic characteristics

(Self-)Employed

Not (self-)employed

Retired

Low education

Medium education

High education 
Tabel 1 (cont'd.): Descriptive sample statistics

Proportion in \% (unweighted)

Health characteristics

Self-perceived general health ('fair or worse')

Two or more chronic diseases

Symptoms of depression

Country groups

Belgium, Denmark, Netherlands, Sweden

(above average activity levels)

Austria, France, Germany, Switzerland

(average activity levels)

Greece, Italy, Spain

(below average activity levels)

$n$

Source: SHARE 2004 (Release 2.0.0). 
Table 2: Results of univariate probit models for the dependent variables 'volunteer work', 'informal help', and 'care' $(\mathrm{n}=27,305)$

\begin{tabular}{|c|c|c|c|c|c|c|c|c|c|}
\hline & \multicolumn{3}{|c|}{ Volunteer work } & \multicolumn{3}{|c|}{ Informal help } & \multicolumn{3}{|c|}{ Care } \\
\hline & $\beta$ & & s.e. & $\beta$ & & s.e. & $\beta$ & & s.e. \\
\hline \multicolumn{10}{|c|}{ Demographic characteristics } \\
\hline Sex (female) & -0.035 & & 0.022 & 0.060 & $* *$ & 0.019 & 0.202 & $* *$ & 0.027 \\
\hline Age $50-64^{\mathrm{a}}$ & 0 & & - & 0 & & - & 0 & & - \\
\hline Age $65-74$ & -0.028 & & 0.029 & -0.290 & $* *$ & 0.025 & -0.118 & $* *$ & 0.036 \\
\hline Age $75+$ & -0.282 & $* *$ & 0.037 & -0.678 & $* *$ & 0.032 & -0.138 & $* *$ & 0.043 \\
\hline Living with a partner & 0.026 & & 0.025 & -0.008 & & 0.021 & 0.042 & & 0.030 \\
\hline \multicolumn{10}{|c|}{ Socio-economic characteristics } \\
\hline (Self-)Employed & -0.237 & $* *$ & 0.031 & -0.059 & $*$ & 0.026 & -0.047 & & 0.037 \\
\hline Not (self-)employed & -0.039 & & 0.031 & -0.107 & $* *$ & 0.026 & -0.021 & & 0.036 \\
\hline Retired $^{\mathrm{a}}$ & 0 & & - & 0 & & - & 0 & & - \\
\hline Low education ${ }^{a}$ & 0 & & - & 0 & & - & 0 & & - \\
\hline Medium education & 0.153 & $* *$ & 0.025 & 0.138 & $* *$ & 0.021 & 0.149 & $* *$ & 0.030 \\
\hline High education & 0.454 & $* *$ & 0.027 & 0.204 & $* *$ & 0.024 & 0.189 & $* *$ & 0.035 \\
\hline
\end{tabular}


Table 2 (cnt'd.): Results of univariate probit models for the dependent variables 'volunteer work', 'informal help', and 'care' (n=27,305)

\begin{tabular}{|c|c|c|c|c|c|c|c|c|c|}
\hline & \multicolumn{3}{|c|}{ Volunteer work } & \multicolumn{3}{|c|}{ Informal help } & \multicolumn{3}{|c|}{ Care } \\
\hline & $\beta$ & & s.e. & $\beta$ & & s.e. & $\beta$ & & s.e. \\
\hline \multicolumn{10}{|l|}{ Health characteristics } \\
\hline Self-perceived general health ('fair or worse') & -0.194 & $* *$ & 0.025 & -0.259 & $* *$ & 0.021 & -0.059 & $*$ & 0.030 \\
\hline Two or more chronic diseases & 0.042 & & 0.023 & 0.111 & $* *$ & 0.020 & 0.022 & & 0.028 \\
\hline Symptoms of depression & -0.113 & $* *$ & 0.027 & 0.009 & & 0.023 & 0.189 & $* *$ & 0.030 \\
\hline \multicolumn{10}{|l|}{ Productive activities } \\
\hline Volunteer work & - & & - & 0.393 & $* *$ & 0.025 & 0.441 & $* *$ & 0.032 \\
\hline Informal help & 0.361 & $* *$ & 0.023 & - & & - & 0.547 & $* *$ & 0.027 \\
\hline Care & 0.503 & $* *$ & 0.035 & 0.674 & $* *$ & 0.033 & - & & - \\
\hline \multicolumn{10}{|l|}{ Country groups } \\
\hline Belgium, Denmark, Netherlands, Sweden & 0.308 & $* *$ & 0.025 & 0.372 & $* *$ & 0.022 & -0.060 & & 0.032 \\
\hline Austria, France, Germany, Switzerland & 0 & & - & 0 & & - & 0 & & - \\
\hline Greece, Italy, Spain & -0.161 & $* *$ & 0.026 & -0.077 & $* *$ & 0.022 & -0.033 & & 0.031 \\
\hline Constant & -1.265 & $* *$ & 0.054 & -0.827 & $* *$ & 0.046 & -2.156 & $* *$ & 0.068 \\
\hline Pseudo- $R^{2}$ & \multicolumn{3}{|c|}{0.091} & \multicolumn{3}{|c|}{0.097} & \multicolumn{3}{|c|}{0.080} \\
\hline
\end{tabular}

Source: SHARE 2004 (Release 2.0.0), authors' calculations. Signifikance: $*<.05 ; * *<.01 .{ }^{\text {a }}$ Reference category. 
Table 3: Results of multivariate probit model for the dependent variables 'volunteer work', 'informal help', and 'care' $(\mathrm{n}=27,305)$

\begin{tabular}{|c|c|c|c|c|c|c|c|c|c|}
\hline & \multicolumn{3}{|c|}{ Volunteer work } & \multicolumn{3}{|c|}{ Informal help } & \multicolumn{3}{|c|}{ Care } \\
\hline & \multicolumn{2}{|l|}{$\beta$} & s.e. & \multicolumn{2}{|l|}{$\beta$} & s.e. & \multicolumn{2}{|l|}{$\beta$} & s.e. \\
\hline \multicolumn{10}{|c|}{ Demographic characteristics } \\
\hline Sex (female) & -0.008 & & 0.022 & 0.076 & $* *$ & 0.019 & 0.204 & $* *$ & 0,026 \\
\hline Age $50-64^{a}$ & 0 & & - & 0 & & - & 0 & & - \\
\hline Age $65-74$ & -0.078 & $* *$ & 0.029 & -0.303 & $* *$ & 0.025 & -0.175 & $* *$ & 0,034 \\
\hline Age $75+$ & -0.373 & $* *$ & 0.036 & -0.713 & $* *$ & 0.031 & -0.286 & $* *$ & 0,042 \\
\hline Living with a partner & 0.028 & & 0.025 & -0.005 & & 0.021 & 0.036 & & 0,029 \\
\hline \multicolumn{10}{|c|}{ Socio-economic characteristics } \\
\hline (Self-)Employed & -0.244 & $* *$ & 0.030 & -0.085 & $* *$ & 0.026 & -0.083 & $*$ & 0,035 \\
\hline Not (self-)employed & -0.055 & & 0.031 & -0.111 & $* *$ & 0.026 & -0.044 & & 0,035 \\
\hline Retired $^{\mathrm{a}}$ & 0 & & - & 0 & & - & 0 & & - \\
\hline Low education ${ }^{\mathrm{a}}$ & 0 & & - & 0 & & - & 0 & & - \\
\hline Medium education & 0.183 & $* *$ & 0.025 & 0.168 & $* *$ & 0.021 & 0.190 & $* *$ & 0,029 \\
\hline High education & 0.497 & $* *$ & 0.027 & 0.272 & $* *$ & 0.024 & 0.291 & $* *$ & 0,033 \\
\hline
\end{tabular}


Table 3 (cont’d.): Results of multivariate probit model for the dependent variables 'volunteer work', 'informal help', and 'care' (n=27,305)

\begin{tabular}{|c|c|c|c|c|c|c|c|c|c|}
\hline & \multicolumn{3}{|c|}{ Volunteer work } & \multicolumn{3}{|c|}{ Informal help } & \multicolumn{3}{|c|}{ Care } \\
\hline & \multicolumn{2}{|l|}{$\beta$} & s.e. & \multicolumn{2}{|l|}{$\beta$} & s.e. & \multicolumn{2}{|l|}{$\beta$} & \multirow[t]{2}{*}{ s.e. } \\
\hline Health characteristics & & & & & & & & & \\
\hline Self-perceived general health ('fair or worse') & -0.229 & $* *$ & 0.025 & -0.283 & $* *$ & 0.021 & -0.129 & $* *$ & 0,029 \\
\hline Two or more chronic diseases & 0.058 & $*$ & 0.023 & 0.117 & $* *$ & 0.020 & 0.050 & & 0,027 \\
\hline Symptoms of depression & -0.092 & $* *$ & 0.027 & 0.022 & & 0.022 & 0.177 & $* *$ & 0,029 \\
\hline \multicolumn{10}{|l|}{ Country groups } \\
\hline Belgium, Denmark, Netherlands, Sweden & 0.352 & $* *$ & 0.025 & 0.400 & $* *$ & 0.022 & 0.062 & $*$ & 0,031 \\
\hline Austria, France, Germany, Switzerland & 0 & & - & 0 & & - & 0 & & - \\
\hline Greece, Italy, Spain & -0.168 & $* *$ & 0.026 & -0.091 & $* *$ & 0.022 & -0.060 & $*$ & 0,030 \\
\hline Constant & -1.154 & $* *$ & 0.053 & -0.751 & $* *$ & 0.045 & -1.886 & $* *$ & 0,064 \\
\hline 21 (Volunteer work - Informal help) & 0.193 & $* *$ & 0.012 & & & & & & \\
\hline p31 (Volunteer work - Care) & 0.232 & $* *$ & 0.015 & & & & & & \\
\hline 332 (Informal help - Care) & 0.308 & $* *$ & 0.014 & & & & & & \\
\hline Likelihood Ratio Test $(\rho 21=\rho 31=\rho 32=0)$ & \multicolumn{3}{|c|}{$\mathrm{Chi}^{2}(3)=876.584$} & & & & & & \\
\hline
\end{tabular}

Source: SHARE 2004 (Release 2.0.0), authors' calculations. Signifikance: $*<.05 ; * * .01$. ${ }^{\text {a }}$ Reference category. 


\section{Discussion Paper Series}

Mannheim Research Institute for the Economics of Aging Universität Mannheim

To order copies, please direct your request to the author of the title in question.

\begin{tabular}{|c|c|c|c|}
\hline Nr. & Autoren & Titel & Jahr \\
\hline $130-07$ & Axel Börsch-Supan & $\begin{array}{l}\text { Nachfrageseitiger Wettbewerb im } \\
\text { Gesundheitswesen }\end{array}$ & 07 \\
\hline $131-07$ & $\begin{array}{l}\text { Florian Heiss, Axel } \\
\text { Börsch-Supan, Michael } \\
\text { Hurd, David Wise }\end{array}$ & $\begin{array}{l}\text { Pathways to Disability: Predicting Health } \\
\text { Trajectories }\end{array}$ & 07 \\
\hline $132-07$ & Axel Börsch-Supan & Rational Pension Reform & 07 \\
\hline $133-07$ & Axel Börsch-Supan & Über selbststabilisierende Rentensysteme & 07 \\
\hline $134-07$ & $\begin{array}{l}\text { Axel Börsch-Supan, } \\
\text { Hendrik Jürges }\end{array}$ & $\begin{array}{l}\text { Early Retirement, Social Security and Well- } \\
\text { Being in Germany }\end{array}$ & 07 \\
\hline $135-07$ & Axel Börsch-Supan & Work Disability, Health, and Incentive Effects & 07 \\
\hline $136-07$ & $\begin{array}{l}\text { Axel Börsch-Supan, } \\
\text { Anette Reil-Held, } \\
\text { Daniel Schunk }\end{array}$ & $\begin{array}{l}\text { The savings behaviour of German households: } \\
\text { First Experiences with state promoted private } \\
\text { pensions }\end{array}$ & 07 \\
\hline $137-07$ & $\begin{array}{l}\text { Hendrik Jürges, } \\
\text { Mauricio Avendano, } \\
\text { Johan Mackenbach }\end{array}$ & $\begin{array}{l}\text { How comparable are different measures of self- } \\
\text { rated health? Evidence from five European } \\
\text { countries }\end{array}$ & 07 \\
\hline $138-07$ & $\begin{array}{l}\text { Hendrik Jürges, } \\
\text { Kerstion Schneider }\end{array}$ & $\begin{array}{l}\text { What can go wrong will go wrong: Birthday } \\
\text { effects and early tracking in the German school } \\
\text { system }\end{array}$ & 07 \\
\hline $139-07$ & Hendrik Jürges & $\begin{array}{l}\text { Does ill health affect savings intentions? } \\
\text { Evidence from SHARE }\end{array}$ & 07 \\
\hline $140-07$ & Hendrik Jürges & $\begin{array}{l}\text { Health inequalities by education, income, and } \\
\text { wealth: a comparison of } 11 \text { European countries } \\
\text { and the US }\end{array}$ & 07 \\
\hline $141-07$ & Hendrik Jürges & $\begin{array}{l}\text { Healthy minds in healthy bodies. An } \\
\text { international comparison of education-related } \\
\text { inequality in physical health among older adults }\end{array}$ & 07 \\
\hline $142-07$ & $\begin{array}{l}\text { Karsten Hank, } \\
\text { Stephanie Stuck }\end{array}$ & $\begin{array}{l}\text { Volunteer Work, Informal Help, and Care among } \\
\text { the 50+ in Europe: Further Evidence for 'Linked' } \\
\text { Productive Activities at Older Ages }\end{array}$ & 07 \\
\hline
\end{tabular}

